Journal of Applied Pharmaceutical Science Vol. 5 (08), pp. 159-166, August, 2015

Available online at http://www.japsonline.com

DOI: $10.7324 / \mathrm{JAPS} .2015 .50825$

ISSN 2231-3354 (cc) BY-NC-SA

\title{
Simultaneous Estimation of Stigmasterol and Withaferin A in Union Total Herbal Formulation Using Validated HPTLC Method
}

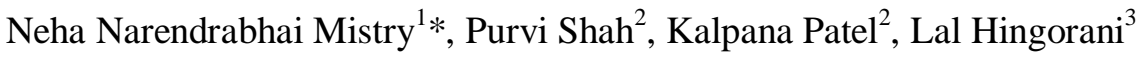 \\ ${ }^{1}$ Department of Quality Assurance, Sardar Patel College of Pharmacy, Bakrol, Gujarat, India. ${ }^{2}$ Department of Quality Assurance, Anand Pharmacy \\ College, Anand, Gujarat, India. ${ }^{3}$ Pharmanza Herbal Pvt. Ltd., Dharmaj, Gujarat, India.
}

\begin{tabular}{|c|c|}
\hline ARTICLE INFO & ABSTRACT \\
\hline Article history: & \multirow{10}{*}{$\begin{array}{l}\text { Union Total is herbal formulation made in the form of capsule which contains two standardized plant extracts } \\
\text { Cissus quadrangularis (CQ) and Withania somnifera (WS). The present work describes development and } \\
\text { validation of High Performance Thin Layer Chromatographic method for simultaneous analysis of Stigmasterol } \\
\text { (STG) in Cissus quadrangularis (CQ) and Withaferin A (WFA) in Withania somnifera (WS). Stigmasterol and } \\
\text { Withaferin A were identified on silica G60 } \mathrm{F}_{254} \text { HPTLC plates by post derivatization technique and robustness } \\
\text { study was performed by applying a central composite design (CCD) with k factor having } 2^{\mathrm{k}} \text { factorial runs, } 2 \mathrm{k} \\
\text { axial experiments and five center points. In HPTLC good separation was obtained with chloroform: methanol: } \\
\text { toluene: formic acid (6.5: } 0.5: 3: 0.25 \mathrm{v} / \mathrm{v} / \mathrm{v} / \mathrm{v} \text { ) as mobile phase and anisaldehyde sulphuric acid as a derivatizing } \\
\text { reagent at detection wavelength } 530 \mathrm{~nm} \text {. Linearity was obtained in the concentration range of } 100-200 \mathrm{ng} / \mathrm{band} \\
\text { for WFA and } 200-700 \mathrm{ng} / \mathrm{band} \text { for STG and the \% recoveries were found in the range of } 100.06 \% \text { to } 100.46 \% \\
\text { for WFA and } 99.97 \% \text { to } 100.94 \% \text { for STG respectively. HPTLC method was found to be sensitive, precise, } \\
\text { accurate and reproducible, which would be of use in quality control of these tablets. }\end{array}$} \\
\hline //04/2015 & \\
\hline Revis & \\
\hline Accepted on: $23 / 05 / 2015$ & \\
\hline Available online: $28 / 08 / 2015$ & \\
\hline Key words: & \\
\hline & \\
\hline formulation, Stigmasterol, & \\
\hline Withaferin A, HPTLC, CCD & \\
\hline & \\
\hline
\end{tabular}

\section{INTRODUCTION}

Osteoporosis, a silent epidemic, is characterized by decreased bone mineral density (BMD), increased risk of fractures and is associated with micro architectural deterioration of bone tissue that results in low bone mass. It has become major health hazard affecting more than 2000 million people, of both sexes and all races worldwide in recent years (Kumar at el., 2010; Jia et al., 2012). According to World Health Organization (WHO), osteoporosis is defined as a bone mineral density that lays 2.5 standard deviations or more below the average value for young healthy women. In osteoporosis, bone loss occurs especially at the trabecular area when the balance of bone remodeling is tipped towards bone resorption. The bone loss is associated with bone biochemical marker changes such as reduction in osteocalcin level, the marker for bone formation and elevation in crosslink C-telopeptide, the marker for bone resorption (Shuid et al., 2012). Last few decades have seen a tremendous increase in the use of traditional medicines globally.

\footnotetext{
* Corresponding Author

Email: neha1990mistry@yahoo.com
}

According to an estimate about $80 \%$ of population the world over depends on traditional medicines (Bhondave et al., 2014). Ecofriendly, bio-friendly, cost-effective and relatively safe herbal medicines have moved from the fringe to the mainstream with increased research in the field of traditional medicine (Sen et al., 2011). Natural products for the management of osteoporosis are largely phytoestrogens which include isoflavones, lignins, flavonoids, and coumestans that share structural and functional similarities with naturally occurring or synthetic estrogens. Phytoestrogens exhibit estrogen-like effects at various reproductive and non-reproductive tissues (Compston, 2014). Cissus quadrangularis is the most common species belonging to the family Vitaceae, commonly known as Hadjod or bonesetter in Hindi due to its bone fracture healing property. The plant is prescribed in the ancient Ayurvedic literature as general tonic and analgesic, with specific bone fracture healing properties due to presence of several new compounds like lipids, stilbenoids, steroids, irridoids and flavanoids (Gupta, 2005; Shah, 2011). Because being an effective remedy in treatment of bone fractures, a range of formulations containing CQ extract either alone or in combinations with other hearths have been marketed (Udupa, 1964; Chopra, 1975). Withania somnifera belonging to family Solanaceae; is also known as Ashwagandha. 
The main constituents of Ashwagandha are alkaloids and steroidal lactones from which withaferin A help to increase expression of osteoblastogenesis and decrease expression of osteoclastogenesis (Gupta, 2011; Anonymous, 1998). Union total capsule is a herbal formulation contains two standardized plant extracts i.e. Cissus quadrangularis $750 \mathrm{mg}$ and Withania somnifera $100 \mathrm{mg}$. It is mainly indicated for fracture healing and osteoporosis. The key challenge in integrating Ayurvedic medicines with the current clinical practice is lack of scientific data and better understanding of efficacy and safety of the herbal formulations. The need of the hour is to evolve a systematic approach and to develop well-designed methodologies for standardization of raw material as well as herbal formulations (Marcus and Grollman et al., 2002; Vaidya et al., 2003). HPTLC has recently emerged as a preferred analytical tool for fingerprints and quantification of marker compounds in herbal drugs because of its simplicity, sensitivity, accuracy, suitability for high throughput screening analysis of herbal medicine. Previously, different methods have been reported for HPTLC estimation of stigmasterol and withaferin A individually or in combination with other markers (shah et al., 2010; Hussains et al., 2012; Badole et al., 2011; Gauttam, 2013). To the best of our knowledge this is the first report on a method for concurrent analysis and estimation of these marker compounds. Therefore, the current study was aimed to determine STG and WFA by HPTLC method using Design of Experiment (DoE) approach for method validation, which will be useful for the proper identification of Union total herbal formulation.

Experimental design procedures are very useful in pharmaceutical development including formulation development and analytical method optimization and validation, and are more effective than the traditional one variable-at-a-time approach (Goupy, 2005). Experimental design methodology has proved to be a useful tool for method validation, as it allows the investigation of simultaneously changing factors. During method validation, ruggedness (different normal conditions) or robustness (small changes introduced deliberately) studies are typically performed with the expected outcome that there is no significant change of the response, allowing the claim of a rugged/robust method.

Moreover, many factors can be screened simultaneously without concerns about interacting and non-interacting effects, as they are usually considered negligible. On evaluation of obtained results, when a factor is not robust, the proposed method can be changed, revalidated or the factor can be controlled. Various experimental designs for robustness study includes Plackett Burman design, factorial, fractional factorial and response surface designs. (Shrinubanu et al., 2007; Hibbert, 2012; Fabre, 1996). This research article focuses on the determination of robustness of HPTLC analytical method by central composite design. Among the various experimental designs, central composite design (CCD) as a response surface design was preferred for prediction of nonlinear response due to its flexibility, in terms of experimental runs and information related to factor's main and interaction effects. CCD combines two level factorial design with a star design and centre points covers the factor space near the centre with more points than at the periphery and allows more number of levels without performing experiments at every combination of factor levels (Beer et al., 1996; Valdimir et al., 2002).

\section{MATERIAL AND METHODS}

\section{Materials and reagents}

Standards namely Stigmasterol (STG) and Withaferin A (WFA) were provided as gift sample from Sigma Life Science (Mumbai) and Pharmanza Herbal Pvt. Ltd (Dharmaj) respectively. Herbal extracts i.e. Cissus quadrangularis (CQ) and Withania somnifera (WS) present in Union total Herbal formulation and Union total capsules were procured from Pharmanza Herbal Pvt. Ltd.; all chemicals and reagents used in the study were of analytical grade and purchased from Merck specialties Pvt. Ltd. Mumbai, India.

\section{Instrumentation and software}

A Camag HPTLC system (Switzerland) comprising of Camag Linomat V semi automatic sample applicator, Camag TLC Scanner IV, Camag (Muttenz, Switzerland) flat bottom and twintrough developing chamber $(10 \times 10 \mathrm{~cm})$, UV cabinet with dual wavelength UV lamp, Hamilton syringe (100 $\mu \mathrm{l})$, Ultrasonic bath (Frontline FS-4, Mumbai, India) and Camag winCATS software were used in the study. Experimental design based robustness testing was carried out by using Design expert software (v 9.0.0.7) Stat-Ease Inc., Minneapolis and remaining calculations were performed by use of Microsoft Excel 2007 software.

\section{Preparation of standard solutions}

A stock solution of STG and WFA were prepared separately by weighing accurately $10 \mathrm{mg}$ of each marker followed by dilution in methanol in $10 \mathrm{ml}$ volumetric flask and volume was made up to the mark with methanol, to obtain a concentration of $1000 \mu \mathrm{g} / \mathrm{ml}$. The standard stock solutions were suitably diluted with methanol to obtain the working standard solutions of STG and WFA.

\section{Preparation of sample solution}

Ten Union total capsules (Herbal formulation) were taken, shell of capsules was removed to get powder and grind into a clean and dry mortar-pestle. An equivalent to $750 \mathrm{mg} \mathrm{CQ}$ extract powder and $100 \mathrm{mg}$ of WS extract powder was transferred to a 10 $\mathrm{ml}$ volumetric flask followed by addition of $10 \mathrm{ml}$ of methanol and sonicated for 30 minutes. This solution will give $500 \mu \mathrm{g} / \mathrm{ml}$ of STG and $120 \mu \mathrm{g} / \mathrm{ml}$ of WFA which was directly used for analysis.

\section{Method Development}

Different solvents in different ratios like methanol, chloroform, ethyl acetate, toluene, glacial acetic acid, formic acid, ammonia, triethylamine and hexane were tried for optimization of 
mobile phase. Suitable volumes of standard and sample solutions were applied to the Pre-coated silica gel $60 \mathrm{~F}_{254} \backslash$ HPTLC plates (E. Merck) as bands of $6 \mathrm{~mm}$ using Linomat V. Application positions were at least $15 \mathrm{~mm}$ from the sides and $8 \mathrm{~mm}$ from the bottom of the plates. Mobile phase components were mixed prior to use and the development chamber was left to saturate with mobile phase vapour for $25 \mathrm{~min}$ before each run. Development of the plate was carried out by the ascending technique to a migration distance of $8 \mathrm{~cm}$. Then the plates were dried in an oven. After drying plate was dipped in anisaldehyde sulphuric reagent and then plates were dried in oven at $120^{\circ} \mathrm{C} \pm 2^{\circ} \mathrm{C}$. Densitometric scanning was done in absorbance reflectance mode at $530 \mathrm{~nm}$ using a deuterium lamp. The slit dimensions were set at $6 \mathrm{~mm} \times$ $0.30 \mathrm{~mm}$, the scanning speed at $20 \mathrm{~mm} / \mathrm{s}$, and the data resolution of $100 \mu \mathrm{m} / \mathrm{step}$. The results were evaluated with the aim of achieving an optimum separation between spots ( $\mathrm{Rs} \geq 1.5$ ), and a migration of spots with $R_{\mathrm{f}}$ values between 0.2 and 0.8 , in order to ensure separation reproducibility.

\section{Method validation}

The method was validated in accordance with $\mathrm{ICH}$ guidelines Q2 (R1) for evaluation of various parameters; linearity, precision, accuracy, LOD and LOQ and robustness.

\section{Linearity}

Linear relationship between peak area and concentration of two markers were evaluated by making five replicate measurements in the concentrations range of 100-600 ng/band for STG and 200-700 ng/band for WFA. Each calibration plots were constructed by plotting the peak area of band versus the concentration of the markers and treated using the method of ordinary least squares regression analysis.

\section{Precision}

Precision of the developed method was studied by performing repeatability, intermediate precision. The repeatability of sample application and measurement of peak area was determined by performing 3 replicate measurements of the same band. The various solutions were applied on HPTLC plates to form bands with 100, 300, and $500 \mathrm{ng} /$ band of WFA and 200, 400, and $600 \mathrm{ng} / \mathrm{band}$ of STG.

\section{Accuracy}

The accuracy was assessed by the methodological recovery studies to check the recovery of the drug at different levels in the formulations by optimized method. It was carried out by adding known amount of standard to samples at 80, 100 and $120 \%$ level and analyzed by the proposed method, in triplicate.

\section{Limit of detection (LOD) and limit of quantitation (LOQ)}

As per ICH guideline, limit of detection and quantitation of the developed method were calculated from the standard deviation of the response $(\sigma)$ and slope of the calibration curve $(\mathrm{S})$ of each drug using the formula; Limit of detection $=3.3 *^{*} \sigma / \mathrm{S}$ and Limit of quantitation $=10 * \sigma / \mathrm{S}$

\section{Specificity}

Specificity of method was ascertained by comparing spectra of formulation, extract and standard. The peak purity was assessed by comparing spectra at three levels, i.e., peak start (S), peak apex (M) and peak end (E) of spot.

\section{Robustness study using experimental design}

The robustness of an analytical procedure refers to its capability to remain unaffected by small and deliberate variations in method parameters. A CCD with $\mathrm{k}$ factors requires $2 \mathrm{k}$ factorial runs, $2 \mathrm{k}$ axial experiments, which is symmetrically spaced at along each variable axis, and at least one center point. The factors and ranges selected for consideration were based on previous univariate studies of method development and chromatographic intuition.

In the present study three factors viz. developing distance (A), band size (B) and Chloroform in total mobile phase (C) were selected. The nominal value for all these three factors, A, B and C, were $8 \mathrm{~cm}, 6 \mathrm{~mm}$ and $6.5 \mathrm{ml}$, respectively. The ranges examined were small deviations from the method settings and the considered response was the $\mathrm{R}$ value of different drugs. Here five different levels $(-\alpha, 1,0,+1,+\alpha)$ of study were carried out by using rotatable CCD. The coded value of $\alpha$ is 1.41. A three-factor small type $\mathrm{CCD}$ requires 15 experiments, including five center points.

The experimental plan of selected factors is reported in Table 2. All experiments were performed in randomized order to minimize the bias effects of uncontrolled factors.

\section{Analysis of union total formulation}

Ten Union total capsules (Herbal formulation) were taken, shells of capsules were removed to get powder and grind into a clean and dry mortar-pestle. An equivalent to $750 \mathrm{mg} C Q$ extract powder and $100 \mathrm{mg}$ of WS extract powder was transferred to a $10 \mathrm{ml}$ volumetric flask followed by addition of $10 \mathrm{ml}$ of methanol and sonicated for 30 minutes. This solution will give 500 $\mu \mathrm{g} / \mathrm{ml}$ of STG and $120 \mu \mathrm{g} / \mathrm{ml}$ of WFA which was then filtered through Whattman filter paper No. 42 wetted with methanol. The resulting solution was directly used for analysis.

\section{RESULT AND DISCUSSION}

\section{Method development}

UV scanning at $400-800 \mathrm{~nm}$ shows that $530 \mathrm{~nm}$ is the suitable wavelength for detection of both markers (Fig. 1).

Various combinations of mobile phase were tried for optimizing the peaks of mentioned markers by trial and error. The final optimized mobile phase used was Chloroform: Methanol: Toluene: Formic acid (6.5: 0.5: 3.0: 0.25; v/v/v) which gave highest resolution and $\mathrm{R}_{\mathrm{f}}$ values of 0.22 and 0.57 for WFA and STG respectively (Fig. 2) 


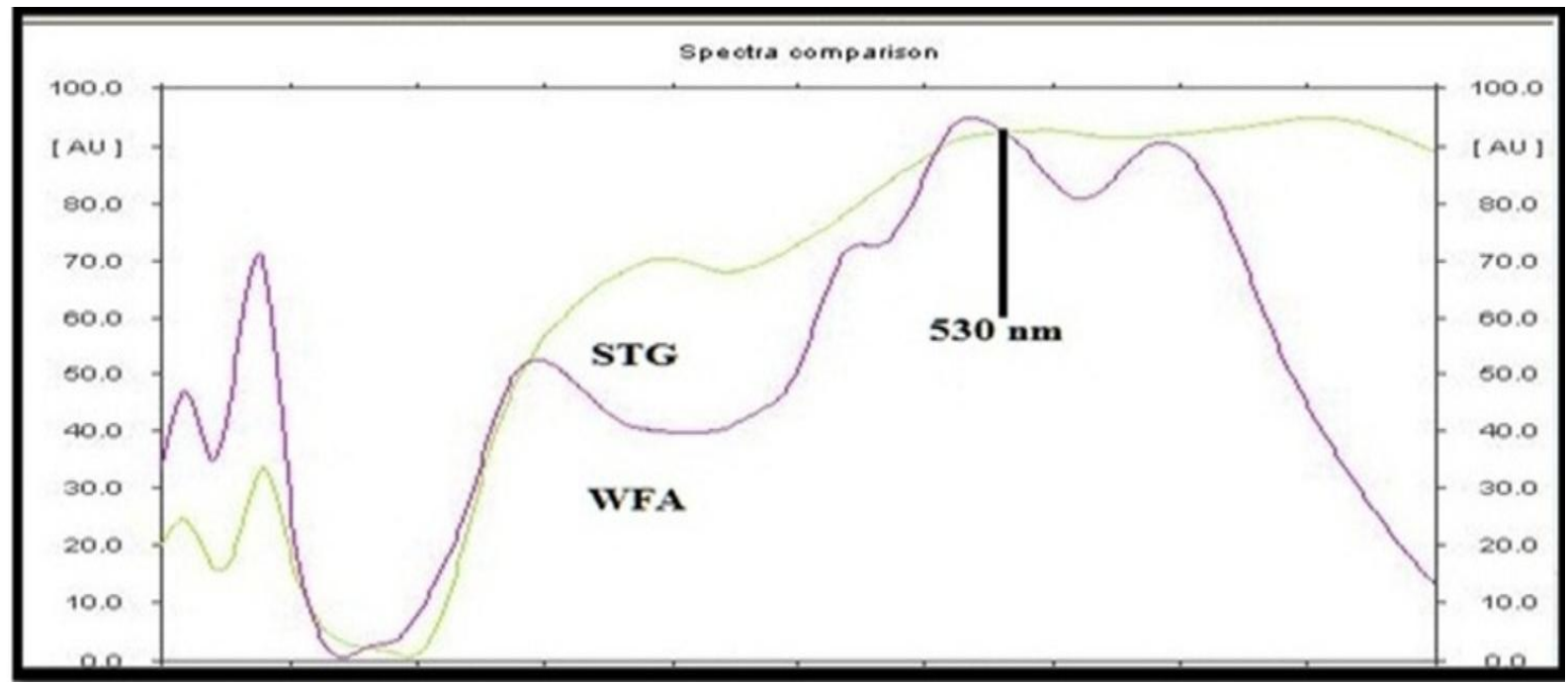

Fig. 1: overlain spectra of stigmasterol and withaferin A at 530nm.

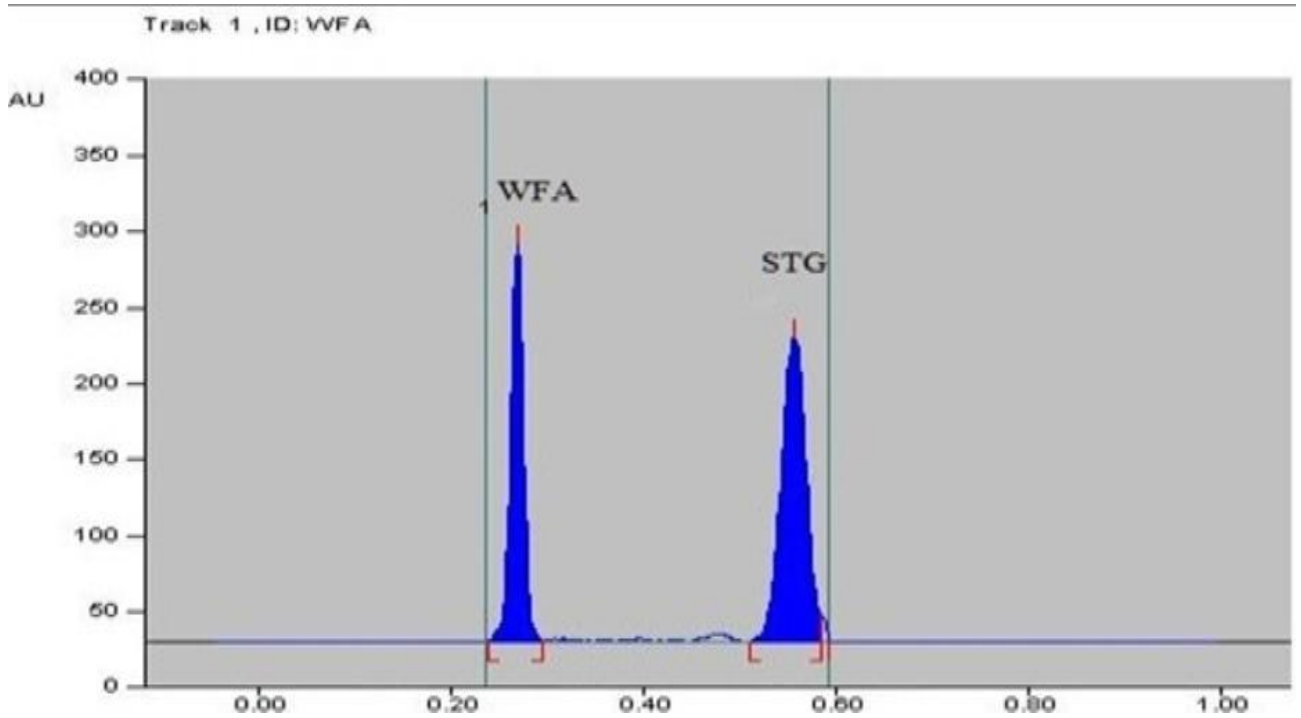

Fig. 2: HPTLC chromatogram of withaferin A and stigmasterol using chloroform: methanol: toluene: formin acid (6.: 0.5: $3: 0.25: \mathrm{v} / \mathrm{v} / \mathrm{v})$ optimized mobile phase.

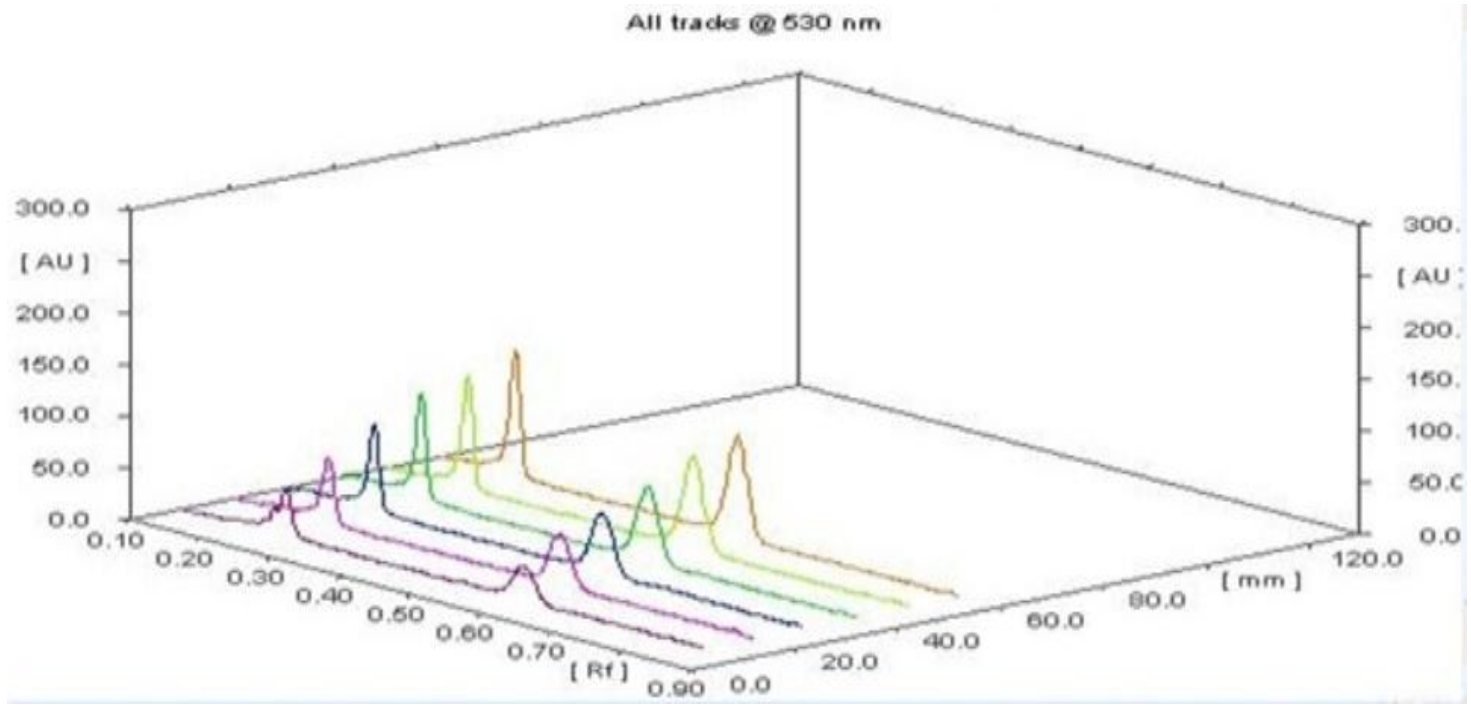

Fig. 3: 3D chromatogram showing Linearity of withaferin a and stigmasterol 


\section{Method Validation Linearity}

The STG and WFA showed good correlation coefficient $\left(r^{2}=0.99681\right.$ for STG and $r^{2=} 0.9960$ for WFA $)$ in the mentioned concentration range 200-700 ng/band for STG and 100-600 ng/band WFA (Fig. 3 and Table 1)

\section{Precision}

Precision of developed method was evaluated by repeatability and intermediate precision, and was expressed as \% relative standard deviation (\%RSD) of the peak area. Repeatability and intermediate precision when carried out by performing three replicates of three different concentrations (100, 300 and 500 ng/band for STG and 200, 400 and $600 \mathrm{ng} /$ band for WFA) showed $\%$ RSD less than $2 \%$ (Table 1) and meet the criteria as per ICH and USP guideline indicating acceptable precision of method.

\section{Accuracy}

The proposed method when used for evaluation of recovery at three concentrations levels, $80 \%, 100 \%$ and $120 \%$ after spiking with standard, showed percentage recovery between $100.06 \%$ to $100.46 \%$ for WFA and $99.97 \%$ to $100.94 \%$ for STG respectively, with acceptable \% RSD, less than 2 (Tab 2).

\section{Limit of detection (LOD) and Limit of quantification (LOQ)}

LOD and LOQ for WFA were $23.818 \mathrm{ng} / \mathrm{band}$ and $72.175 \mathrm{ng} / \mathrm{b}$ and and for STG were $10.049 \mathrm{ng} / \mathrm{band}$ and 30.454 $\mathrm{ng} / \mathrm{band}$ respectively.

\section{Specificity}

The peak purity of STG and WFA assessed by comparing their respective spectra at the peak start (S), apex (M), and peak end (E) positions of the band and results obtained were depicted in Figure 4.

\section{Robustness by using experimental design}

Experimental results were computed by design expert trial version 9.0.0.7. The coefficients of the second-order polynomial model were estimated by the least squares regression. The equation models for $\mathrm{Y}$ for different drugs are shown in Tab. 3.
Here positive sign indicates synergistic effect, while a negative sign indicates antagonistic effect. The model was validated by the analysis of variance (ANOVA). In the present study, the value of adequate precision, (depicts the value of signal to noise ratio) greater than $4 \%$ is desirable; Ratio of 18.074 indicates an adequate signal and model can be used to navigate the design space. The value coefficient of variation (CV) (measures the reproducibility of the model) less than $10 \%$ is desirable and the $\mathrm{P}$ value of the models ( $\mathrm{p}<0.05$ is required) these all were in desirable limits (Table 3 ). It reveals that the model represents the phenomenon quite well and the variation of the response was correctly related to the variation of the factors, showing a good agreement between experimental and predicted values. The interpretation of the results has to start from the analysis of the whole model equation rather than from the analysis of the single coefficients; it is important, for the RSM, to consider also the factors whose coefficients are statistically non-significant. For this reason the analysis of the response surface plot is necessary. Here, predicted models are presented in the form of perturbation plots for better understanding of results (Figure 5). These graphs give the idea about how the response changes as each factor moves from its defined reference value, with all other factors held constant. A steep slope or curvature in a factor indicates that the response is sensitive to that factor. Here, the plots show that factor $\mathrm{C}$ is mostly influencing the $\mathrm{R}_{\mathrm{f}}$ value of all drugs compare to factor $\mathrm{A}$ and B. As shown in Figure 6 (A-D), the analysis produces three-dimensional graphs of RSM by plotting the response model against two of the factors, while the third is held constant at a specified level. Figure 6(A) and 6(C) shows a graphical representation of the variation of response as the function of $\mathrm{A}$ and $\mathrm{C}$, while $\mathrm{B}$ is maintained constant. An increase in the chloroform content results in an increase in $\mathrm{R}_{\mathrm{f}}$ value of WFA ( $\mathrm{Y}$ ) and STG $(\mathrm{Y})$, while developing distance and band size had no significant effect on the response shown in fig 6 (B). Here, we selected the plots which represent the pronouncing effect on the response. Similarly, analogous interpretation may be derived by examining different plots from Figure 6 (A-D). In conclusion, the analysis of response surface confirms that $\mathrm{Y}$ is not robust for factor $\mathrm{C}$, thus a precautionary statement should be included in the analytical procedure for the same.

Table. 1: Analytical parameters of proposed HPTLC method for simultaneous estimation of WFA and STG.

\begin{tabular}{|c|c|c|}
\hline PARAMETERS & WFA & STG \\
\hline \multicolumn{3}{|l|}{ LINEARITY $^{\text {a }}$} \\
\hline Calibration range (ng/band) & $100-600$ & $200-700$ \\
\hline Correlation coefficient & 0.9960 & 0.9931 \\
\hline Slope $\pm \mathrm{SD}^{\mathrm{b}}$ & $1.7478 \pm 0.0123$ & $3.1524 \pm 0.0046$ \\
\hline CI of slope ${ }^{c}$ & $1.595-1.900$ & $2.788-3.518$ \\
\hline Intercept $\pm \mathrm{SD}^{\mathrm{b}}$ & $769.430 \pm 12.615$ & $257.680 \pm 9.600$ \\
\hline CI of intercept ${ }^{\mathrm{c}}$ & $709.896-828.962$ & $81.951-433.409$ \\
\hline Bartlett's test ${ }^{\mathrm{d}}\left(\chi^{2}\right)$ & 0.002181 & 0.000089 \\
\hline \multicolumn{3}{|l|}{ SENSITIVITY (ng/band) } \\
\hline Limit of detection & 23.819 & 10.0499 \\
\hline Limit of quantification & 72.176 & 30.455 \\
\hline \multicolumn{3}{|l|}{ PRECISION (\%RSD, n=3) } \\
\hline Repeatability & $0.235-1.260$ & $0.632-1.228$ \\
\hline Intermediate precision & $0.744-1.507$ & $0.749-0.952$ \\
\hline ACCURACY $($ Mean \pm SD) & $100.06-100.46$ & $99.97-100.94$ \\
\hline
\end{tabular}


Table. 2: CCD model for robustness study with obtained responses.

\begin{tabular}{|c|c|c|c|c|c|c|}
\hline \multirow[b]{2}{*}{ Run } & \multirow[b]{2}{*}{ Space Type } & \multicolumn{3}{|c|}{ FACTORS } & \multicolumn{2}{|c|}{ RESPONSE } \\
\hline & & $\begin{array}{l}\text { Developing distance } \\
(\mathbf{c m})\end{array}$ & Band size (mm) & $\begin{array}{l}\text { Chloroform content in total } \\
\text { mobile phase }(\mathrm{ml})\end{array}$ & $\begin{array}{l}R_{f} \text { value of } \\
\text { WFA }\end{array}$ & $\begin{array}{l}R_{f} \text { value of } \\
\text { STG }\end{array}$ \\
\hline 1 & Factorial & -1 & 1 & 1 & 0.24 & 0.59 \\
\hline 2 & Factorial & -1 & -1 & -1 & 0.2 & 0.55 \\
\hline 3 & Center & 0 & 0 & 0 & 0.22 & 0.57 \\
\hline 4 & Axial & -1.41 & 0 & 0 & 0.22 & 0.56 \\
\hline 5 & Axial & 0 & -1.41 & 0 & 0.22 & 0.57 \\
\hline 6 & Factorial & 1 & -1 & 1 & 0.24 & 0.59 \\
\hline 7 & Axial & 1.41 & 0 & 0 & 0.23 & 0.59 \\
\hline 8 & Center & 0 & 0 & 0 & 0.22 & 0.57 \\
\hline 9 & Axial & 0 & 0 & 1.41 & 0.25 & 0.62 \\
\hline 10 & Center & 0 & 0 & 0 & 0.23 & 0.58 \\
\hline 11 & Axial & 0 & 0 & -1.41 & 0.18 & 0.52 \\
\hline 12 & Center & 0 & 0 & 0 & 0.21 & 0.56 \\
\hline 13 & Factorial & 1 & 1 & -1 & 0.2 & 0.55 \\
\hline 14 & Center & 0 & 0 & 0 & 0.22 & 0.57 \\
\hline 15 & Axial & 0 & 1.41 & 0 & 0.23 & 0.58 \\
\hline
\end{tabular}

$\mathrm{n}=3$ replicates, WFA: withaferin A, STG: stigmasterol, CCD: central composite design

Table. 3: Predicted response models and statistical parameters obtained from ANOVA for CCD

\begin{tabular}{lll}
\hline Response $\left(\mathbf{R}_{\mathbf{f}}\right.$ value) & WFA & STG \\
\hline Type of model & Linear & 2 factor interaction (2FI) \\
\hline Polynomial equation model for $\mathrm{Y}$ & $0.22+1.768 \mathrm{E}-003 \mathrm{~A}+1.768 \mathrm{E}-003 \mathrm{~B}+0.022 \mathrm{C}$ & $0.57+0.011 \mathrm{~A}+3.536 \mathrm{E}-003 \mathrm{~B}+0.035 \mathrm{C}+0.015 \mathrm{AB}+$ \\
& & $3.536 \mathrm{E}-003 \mathrm{AC}+0.011 \mathrm{BC}$ \\
Model p value & 0.0001 & 0.0001 \\
\% CV & 2.86 & 1.02 \\
Adequate precision & 19.411 & 31.429 \\
R-Squared & 0.902 & 00.963 \\
Adj R-Squared & 0.876 & 0.935 \\
Pred R-Squared & 0.824 & 0.897 \\
PRESS & $7.906 \mathrm{E}-004$ & $7.567 \mathrm{E}-004$ \\
\hline
\end{tabular}

Table. 4: Analysis of Union Total herbal formulation.

\begin{tabular}{cccc}
\hline Standards & Label claim $(\mathbf{m g})$ & \% w/w Amount found $(\mathbf{M e a n})^{\mathbf{a}}$ & \% RSD \\
\hline WFA & 1.35 & 100.239 & 0.722 \\
STG & 5.625 & 99.667 & 0.116 \\
\hline
\end{tabular}

$\% \mathrm{RSD}=$ relative standard deviation, ${ }^{\mathrm{a}} \mathrm{n}=3$ replicates
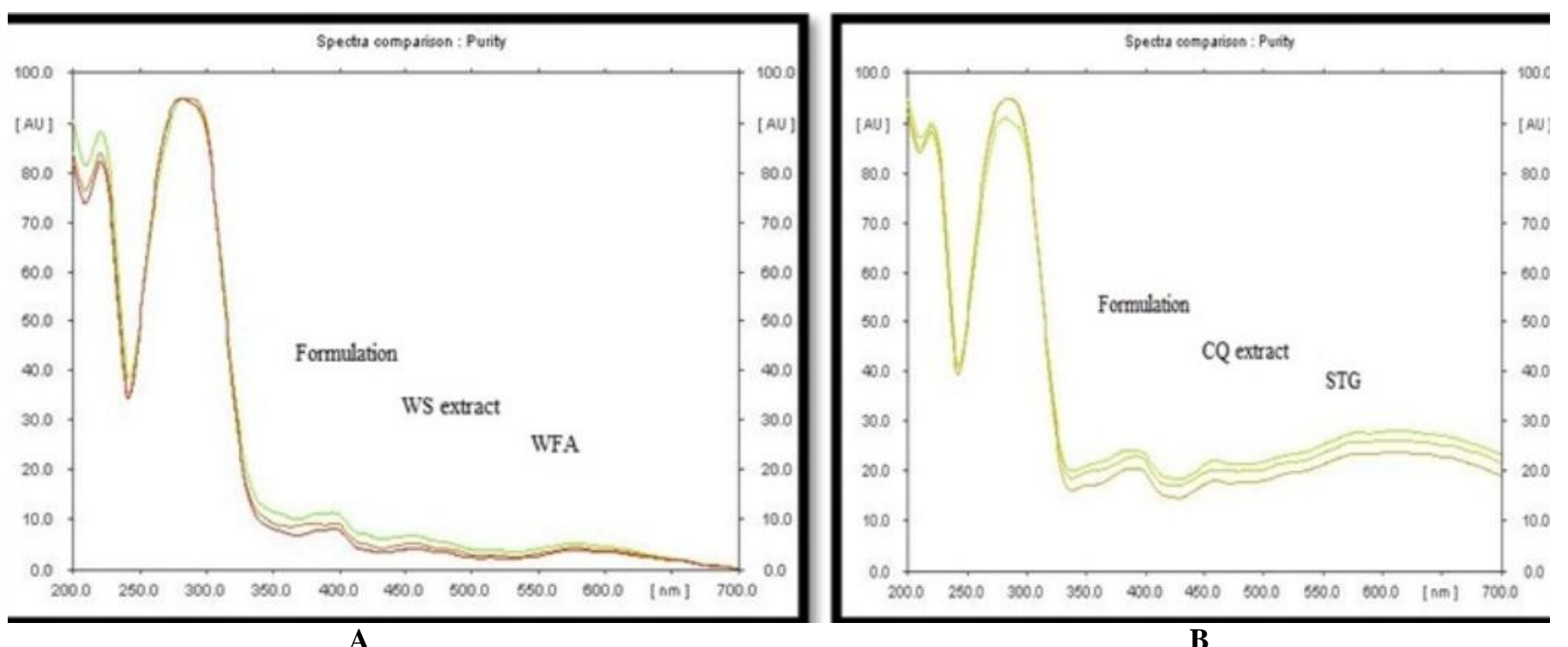

Fig. 4: overlain peak purity spectra of (A) formulation, WS extractand WFA (B) formulation, CQ extract and STG. 

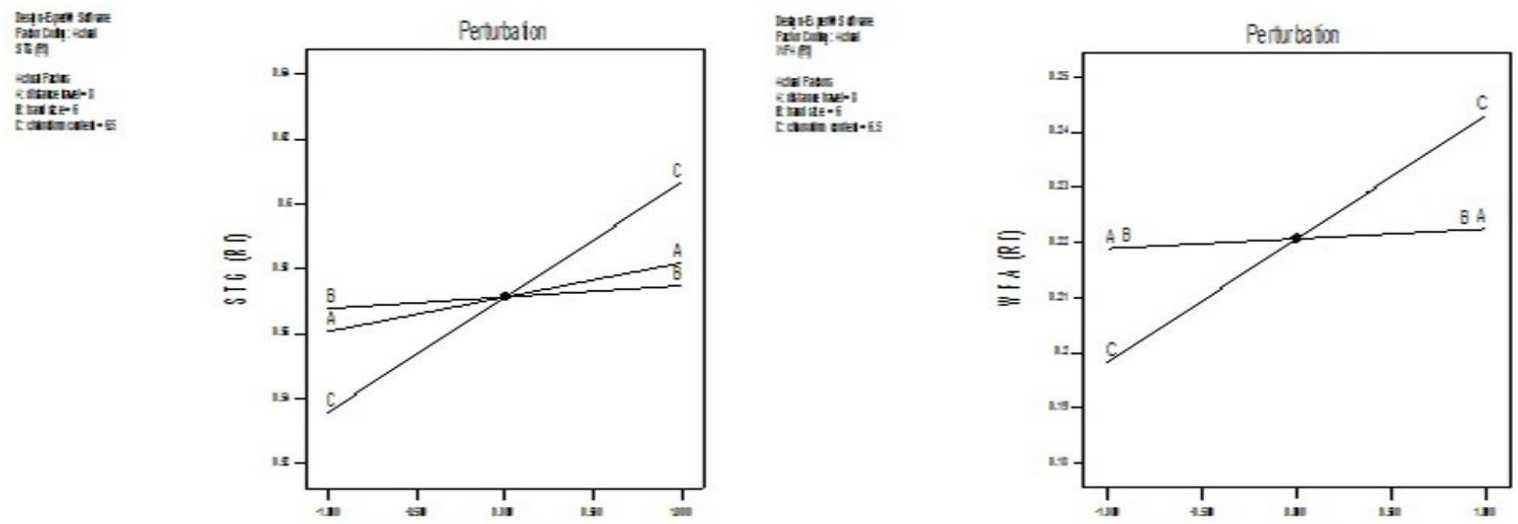

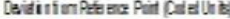

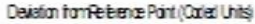

Fig. 5: Perturbation graph showing the effect of each factor $A, B$, and $C$ on $(A) R_{f}$ value of WFA, $(B) R_{f}$ value of $S T G$.

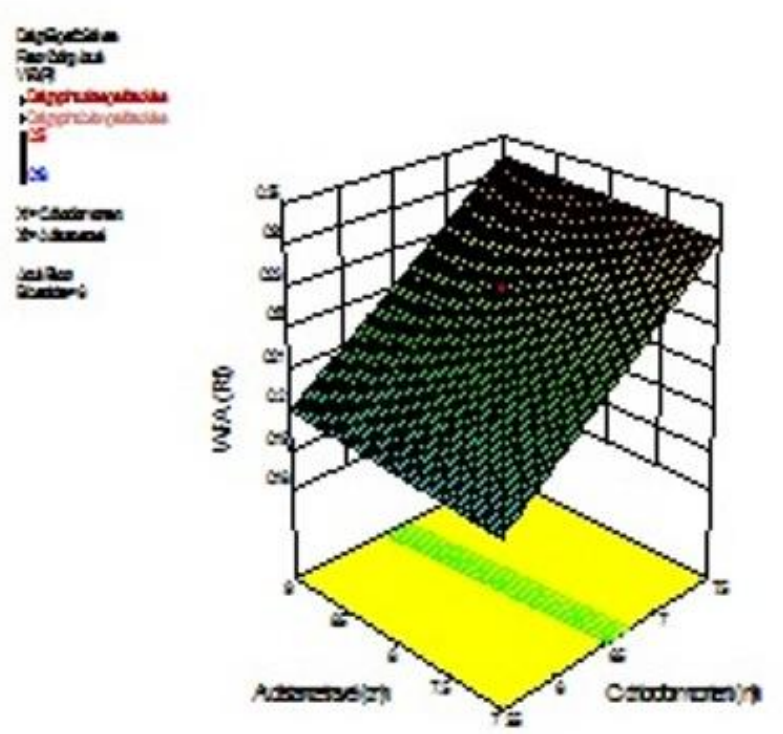

A

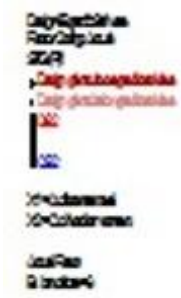

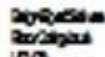

$\cos 20$

Nindanatein

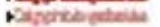

$\| \leq$

teanta.

canes

exatrones:

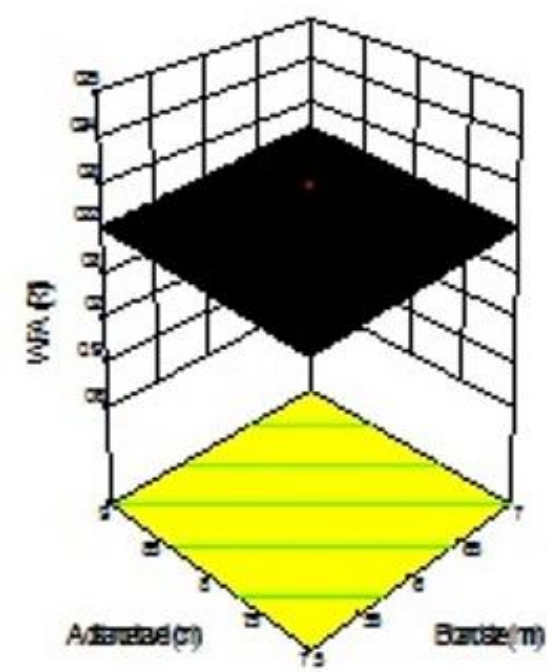

B

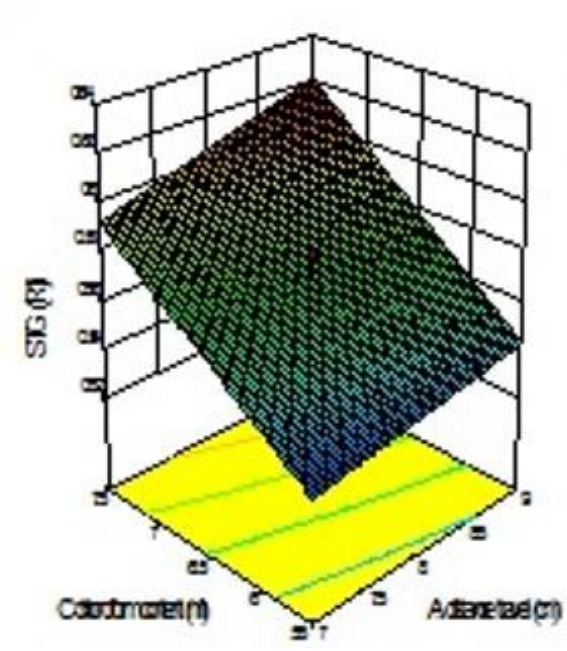

C

Fig. 6: three- dimensional plot of the RSM for Y (R fvlue)

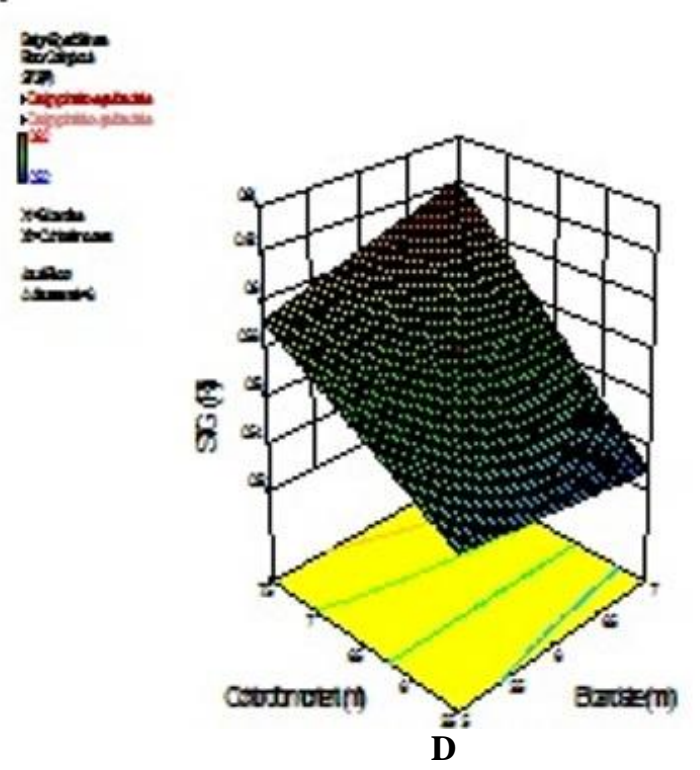




\section{Analysis of Union Total formulation}

Herbal formulations; Withania somnifera $100 \mathrm{mg}$ (WFA $1.35 \mathrm{mg}$ ) and Cissus quadrangularis $750 \mathrm{mg}$ (STG $5.625 \mathrm{mg}$ ) when analyzed in triplicate using the developed method, showed only two peaks of WFA and STG at Rf value 0.22 and 0.57 respectively in the chromatogram of formulation indicating no interference of the excipients.

\section{SUMMARY AND CONCLUSION}

The results indicate that the proposed HPTLC method is novel, rapid, simple, specific, economical and reliable for simultaneous analysis of WFA and STG. The method was validated in accordance with ICH guidelines.

The measured signal was shown to be precise, accurate, and linear over the concentration range (100-600 ng/band and 200$700 \mathrm{ng} / \mathrm{band}$ ) with a correlation coefficient better than 0.9960 . The mean recovery found for mentioned drugs are within the range of 99.66 to 100.239 using HPTLC method. The \%RSD was also less than $2 \%$ showing high degree of precision of the proposed method. The application of CCD on robustness was to study simultaneous variation of effects on responses. CCD was applied to design the experimental program by evaluating the effects of developing distance, chloroform content in total mobile phase, and band size.

The results reveal that the chloroform content of total mobile phase has a significant effect on $R_{f}$ value of each drug.

This study reveals that highly precise, accurate, sensitive, and specific HPTLC method was developed for simultaneous estimation of WFA and STG. Furthermore, the same methodology can be applied for quality control testing and routine analysis of union total formulation.

\section{ACKNOWLEDGEMENT}

We are highly grateful to Pharmanza Herbal Pvt. Ltd., Dharmaj, for providing WFA, STG, CQ extract, WS extract and Union total herbal formulation.

\section{REFERENCES}

Kumar M, Rawat P, Dixit P, Mishra D, Gautam A, Pandey R, et al. Anti-osteoporotic constituents from Indian medicinal plants. Phytomedicine, 2010; 17:993-999.

Jia M, Nie Y, Cao D, Xue Y, Wang J, Zhao L, et al. Potential Antiosteoporotic Agents from Plants: A Comprehensive Review. Evid Based Compl Altern Med, 2012; Article ID 364604:1-28.

Shuid AN, Mohamed N, Mohamed IN, Othman F, Suhaimi F, Ramli ESM, et al. Nigella Sativa: A Potential Antiosteoporotic Agent. Evid Based Compl Altern Med, 2012; Article ID 696230:1- 6.

Bhondave P, Potawale S, Gabhe S, Harsulkar A. A rapid and simple high performance thin layer chromatographic method for simultaneous analysis of $B$-sitosterol-D-glucoside, gallic acid, withaferin A and withanolide $\mathrm{A}$ in Ashvagandharishta. Journal of Applied Pharmaceutical Science, 2014; 4:082-087.

Sen S, Chakraborty R, Dev B. Challenges and opportunities in the advancement of herbal medicine: India's position and role in a global context. J Of herb Med, 2011; 1: 67-75.

Compston J. The Use of Combination Therapy in the Treatment of Postmenopausal Osteoporosis. Endocri, 2012; 4:11-8.
Gupta AK, 2005. Quality standards of Indian medicinal plants, New Delhi: Indian council of medical research, volume 2, 62-69.

Shah U. Cissus quadrangularis: Phytochemicals, Traditional Uses And Pharmacological Activities-A Review. Int J Pharm Pharm Sci, $2011 ; 3: 41-44$

Udupa K, Prasad G. Further studies on the effect of Cissus quadrangularis in accelerating fracture healing. Indian J Med Re, 1964; 52:26-35.

Chopra S, Patel M, Gupta L, Datta L. Studies on Cissus quadrangularis in experimental fracture repair: effect on chemical parameters in blood. Ind J Med Res, 1975; 63:824-8.

Gupta AK, 2011. Quality standards of Indian medicinal plants. New Delhi: Indian council of medical research, volume 9, 356-367.

Anonymous, 1998. Indian Herbal Pharmacopoeia. New Delhi: Regional research laboratory and Indian drug manufacturers' association, Volume 1, 167-168.

Marcus D, Grollman A. Botanical medicines: The need for new regulations. N Engl J Med, 2002; 347:2073-2076

Vaidya R, Vaidya A, Patwardhan B, Tillu G, Rao Y. Ayurvedic pharmacoepidemiology: A proposed new discipline. J Assoc Physicians India, 2003; 51:528.

Shah U, Patel S, Patel P, Hingorani L and Jadhav R. Development and Validation of a Simple Isocratic HPLC Method for Simultaneous Estimation of Phytosterols in Cissus quadrangularis. Indian j. of pharm. Sci, 2010; 72:753-758.

Hussain S, Sheeba F and Mohammad A. Simultaneous HPTLCUV530 nm analysis and validation of bioactive lupeol and stigmasterol in Hygrophila auriculata. Asian Pacific Journal of Tropical Biomedicine, 2012; S612-S617.

Badole M, Dighe V and Charegaonkar G. Simultaneous quantification of $\beta$-amyrin and stigmasterol in Putranjiva roxburghii by high-performance thin-layer chromatography. International Journal of Pharma and Bio Sciences, 2011; 2:346-352.

Gauttam V. High performance thin layer chromatography method for simultaneous estimation of vicine, trigonelline and withaferin $A$ in a polyherbal antidiabetic formulation, International Journal of Pharmacy and Pharmaceutical Sciences, 2013; 5:367-371.

Goupy J, What kind of experimental design for finding and checking robustness of analytical methods?. Analytica chimica acta, 2005; 544:184-190.

Srinubabu G, Raju C, Sarath N, Kumar P, Rao J. Development and validation of a HPLC method for the determination of Voriconazole in pharmaceutical formulation using experimental design. Talanta, 2007; 71:1424-1429.

Hibbert D, Experimental design in chromatography: A tutorial review. J. Chromatogr. B. 2012; 910:2-13.

Fabre H, Robustness testing in liquid chromatography and capillary electrophoresis. Journal of pharmaceutical and biomedical analysis, 1996; 14:1125-1132.

De Beer JO, Vandenbroucke CV, Massart DL, De Spiegeleer BM. Halffraction and full factorial designs versus central composite design for retention modeling in reversed phase ion-pair liquid chromatography. J Pharm Biomed Anal, 1996; 14:525

Vladimir W, Anthony F. Central composite design as a powerful optimization technique for enantioresolution of the rac-11dihydrooracin-the principal metabolite of the potential cytostatic drug oracin. J Biochem Biophys Methods, 2002; 54:377-90.

ICH Harmonized Tripartite Guideline, Validation of analytical procedures: Text and Methodology Q2 (R1), International Conference on Harmonization. Geneva, Switzerland, 2005.

\section{How to cite this article:}

Neha Narendrabhai Mistry, Purvi shah, Kalpana Patel, Lal Hingorani. Simultaneous Estimation of Stigmasterol and Withaferin A in Union Total Herbal Formulation Using Validated HPTLC Method. J App Pharm Sci, 2015; 5 (08): 159-166. 